\title{
The normal electrocardiogram as a predictor of left ventricular function in patients with coronary artery disease
}

\author{
MARK H. SWARTZ, AUGUSTO D. PICHARD, JOSE MELLER, \\ LOUIS E. TEICHHOLZ, AND MICHAEL V. HERMAN
}

From the Division of Cardiology, Department of Medicine of The Mount Sinai Hospital and The Mount Sinai School of Medicine of The City University of New York, New York, U.S.A.

Fifty-five consecutive patients with a normal resting electrocardiogram and coronary artery disease were examined to determine left ventricular function. Fifty-two (95\%) had no evidence of left ventricular asynergy; 3 patients had only mild hypokinesis. Of this group of patients, 25 (47\%) had one vessel disease, $17(30 \%)$ had two vessel disease, and $13(23 \%)$ had three vessel disease.

Significant left ventricular asynergy was not not found in patients with coronary artery disease and normal electrocardiograms. In addition, a normal electrocardiogram was not related to the number of coronary arteries involved.

Left ventricular function is one of the important factors in the prognosis of patients with coronary artery disease. Patients with normal haemodynamic states and normal ventriculograms have a far better prognosis than those with abnormal haemodynamic states and abnormal ventriculograms (Bruschke et al., 1973; Burggraf and Parker, 1975). The assessment of left ventricular function is often made from non-invasive methods such as the chest $x$-ray, electrocardiogram, vectorcardiogram, systolic time intervals (Weissler et al., 1972), echocardiogram (Jacobs et al., 1973), and B-ultrasonography of the heart (Teichholz et al., 1973).

The value of pathological $Q$ waves in the electrocardiogram as predictors of the presence, site, and severity of left ventricular asynergy in the majority of patients is accepted by most investigators (Proudfit et al., 1966; Bordia et al., 1970; Welch et al., 1970; Hilsenrath et al., 1972; Williams et al., 1973; Miller et al., 1974; Bodenheimer et al., 1975). Furthermore, the presence of $Q$ waves makes reversibility of left ventricular asynergy unlikely by nitroglycerin administration (Helfant et al., 1974; Banka et al., 1974) or by myocardial revascularization (Chatterjee et al., 1973).

However, the value of a normal electrocardiogram in predicting normal left ventricular function in patients with coronary artery disease particularly has not been evaluated. Because of its pronounced

Received for publication 6 September 1976 clinical and epidemiological significance, a study was designed to test its validity.

\section{Subjects and methods}

A consecutive retrospective review of patients with angiographically documented coronary artery disease and normal resting electrocardiograms was made in 55 subjects. A normal resting 12 lead electrocardiogram was defined by the conventional criteria (Simonson, 1961), in the absence of pathological $Q$ waves, hypertrophy patterns, conduction abnormalities or abnormalities of repolarisation (e.g. non-specific ST-T wave changes). The electrocardiograms were analysed by three different cardiologists and accepted only if they were considered normal by all observers. Patients with valvular heart disease and cardiomyopathies were excluded.

Selective left and right coronary angiography was accomplished by the Sones or Judkins technique. Coronary artery disease was defined as the presence of one, two, or three coronary arteries with at least 70 per cent obstruction of their lumen.

Left ventricular end-diastolic pressure was recorded in the resting state. Left ventriculography was performed with the patient in a $30^{\circ}$ right anterior oblique projection. A frame-by-frame motion analysis (Herman et al., 1967) was carried out, and the ventricle was divided into inferior, apical, and anterior segments. The size, shape, and 


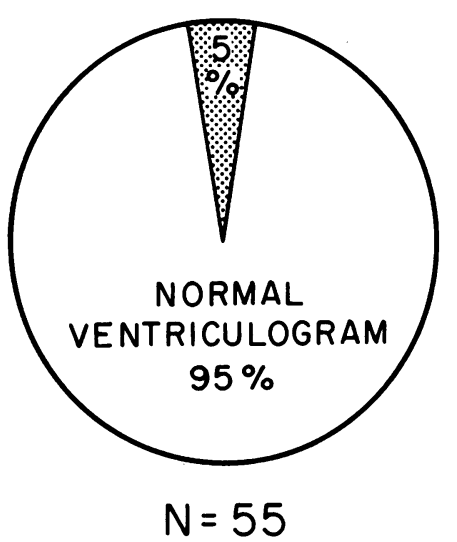

Fig. 1 Left ventricular function in patients with coronary artery disease and normal electrocardiogram. $n=$ number of patients.

contractility pattern was noted, and the presence or absence of asynergy was identified. Ejection fractions were calculated from the Dodge formula (Sandler and Dodge, 1968).

\section{Results}

Fifty-five consecutive patients with normal electrocardiograms and angiographically-proved coronary artery disease constitute the group of this analysis. There were 52 men, and 3 women with a mean age of 49 years (range: 34 to 63 ). Of this group of patients, all were symptomatic of angina pectoris for periods of 6 months to 12 years. Twenty-nine were classified by cardiac status in class II by the criteria of the New York Heart Association, 20 in class III, and 6 in class IV.

Fifty-two patients $(95 \%)$ with normal resting electrocardiograms and significant coronary artery disease had no evidence of left ventricular asynergy and their ventriculogram was considered normal (Fig. 1). One patient had mild hypokinesis involving the apical segment, and 2 patients had mild hypokinesis of the inferior aspect of the left ventricle. No patient had severe hypokinesis, akinesis, or dyskinesis.

The ejection fractions were normal for the entire group. Left ventricular end-diastolic pressure was above $12 \mathrm{mmHg}$ in 12 of 55 patients. It was normal in the 3 patients with mild asynergy.

In this group of patients with coronary artery disease and normal electrocardiograms, $25(47 \%)$ had single vessel disease and $17(30 \%)$ had double vessel disease (Fig. 2). Though 47 per cent had single vessel disease, 53 per cent had significant double and triple vessel disease in the presence of a

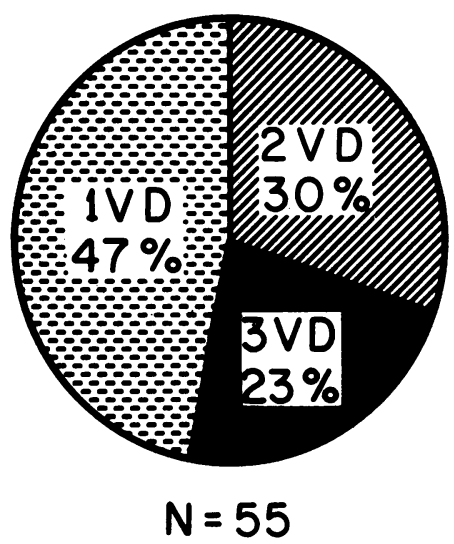

Fig. 2 Severity of coronary artery disease in patients with normal electrocardiograms. $n=$ number of patients.

normal electrucardiogram. Of the 3 patients with mild hypokinesis, 2 had triple vessel disease and 1 had double vessel disease.

\section{Discussion}

Our data indicate that a normal electrocardiogram in the evaluation of the patient with angina pectoris predicts with a high degree of reliability normal left ventricular contractility without asynergic segments. Significant left ventricular asynergy was not found in this group of 55 patients. Ninety-five per cent of these patients had normal ventricular contraction, while 5 per cent showed only mild hypokinesis. At the same time, a normal electrocardiogram had no correlation with the presence or degree of coronary artery disease present. Other investigators (Likoff et al., 1975; Bjork et al., 1967; Martinez-Rios et al., 1970) have clearly shown that significant coronary artery disease may exist in the presence of a normal resting electrocardiogram. Even patients with significant left main coronary artery stenosis may have a normal resting electrocardiogram (Cohen et al., 1972). The absence of electrocardiographic signs of ischaemia could be related to the presence of adequate blood supply to the affected myocardium at rest (Martinez-Rios, et al., 1970) or to inadequate sensitivity of the standard electrocardiogram to detect early stages of myocardial ischaemia.

Recently, other groups (Hilsenrath et al., 1975; Gottlieb et al., 1975) have evaluated the relation of left ventricular contraction pattern in patients with coronary artery disease with the electrocardiogram and vectorcardiogram. Of 230 patients (Hilsenrath et al., 1975), 53 had normal electrocardiograms and 
vectorcardiograms. Of these, $38(72 \%)$ had normal left ventricular contraction. Nine patients $(17 \%)$ had anteroapical asynergy and $4(7 \%)$ had isolated inferoposterior asynergy. In 2 patients, both inferoposterior as well as anteroapical asynergy was shown. In another study (Gottlieb et al., 1975), 71 to 78 per cent of patients with equal or greater than 75 per cent coronary occlusion and normal electrocardiograms had normal ventriculograms. The difference between these studies and ours can be attributed to the difference in the definition of a normal electrocardiogram. Our study excluded all those with ST-T wave changes, among which asynergy is a prevalent finding.

It is of note that a raised left ventricular end diastolic pressure was noted in 12 of the 55 patients having normal electrocardiograms and normal ventriculograms. This finding may best be explained by a decrease in the left ventricular diastolic compliance in these patients with coronary artery disease which may occur earlier in some patients than the wall motion abnormalities.

The presence of a normal electrocardiogram, and its correlation with a normal left ventriculogram is of special relevance in the clinical evaluation of the patient with coronary artery disease. Medical therapy of angina in these patients is associated with a better prognosis as compared with those patients with abnormal left ventriculogram (Bruschke, et al., 1973; Burggraf and Parker, 1975). This prognosis will depend mainly on the number of coronary arteries involved (Friesinger et al., 1970; Bruschke et al., 1973). Furthermore, if revascularization surgery proves to be effective in the preservation of jeopardized myocardium, this objective will be best accomplished in the patient with a normal left ventricle.

In conclusion, a normal electrocardiogram in patients with coronary artery disease is a most valuable predictor of a normal left ventricle just as an abnormal electrocardiogram is a reliable predictor of left ventricular asynergy.

\section{References}

Banka, V., Bodenheimer, M., and Helfant, R. (1974). Determinants of reversible asynergy: effect of pathologic $Q$ waves, coronary collaterals, and anatomic location. Circulation, 50, 714-719.

Bjork, L., Cullhed, I., and Hallen, A. (1967). Cine-angiographic studies of left ventricle in patients with angina pectoris. Circulation, 36, 868-877.

Bodenheimer, M., Banka, V., and Helfant, R. (1975). Q waves and ventricular asynergy. Predictive value and hemodynamic significance of anatomical localization. American Fournal of Cardiology, 35, 615-618.

Bordia, A., Easley, R., Heinle, R., and Goldstein, A. (1970). Correlation of ventriculogram with vectocardiogram and electrocardiogram in coronary artery disease (abstract). Circulation, 41 and 42, Suppl. III, 138.
Bruschke, A., Proudfit, W., and Sones, F. (1973). Progress study of 590 consecutive non-surgical cases of coronary disease followed 5 to 9 years. II. Ventriculographic and other correlations. Circulation, 47, 1154-1163.

Burggraf, G., and Parker, J. (1975). Prognosis in coronary artery disease. Angiographic, hemodynamic and clinical features. Circulation, 51, 146-156.

Chatterjee, K., Swan, H., Parmley, W., Sustaita, H., Marcus, H., and Matloff, J. (1973). Influence of direct myocardial revascularization on left ventricular asynergy and function in patients with coronary heart disease. Circulation, 47, 276-286.

Cohen, M., Cohn, P. F., Herman, M., and Gorlin, R. (1972). Diagnosis and prognosis of main left coronary artery obstruction. Circulation, 45 and 46, Suppl. I, 57-65.

Friesinger, G., Page, E., and Ross, R. (1970). Prognostic significance of coronary arteriography. Transactions of the Association of American Physicians, 83, 78-92.

Gottlieb, R., Duca, P., Kasparian, H., Scariato, A., and Brest, A. (1975). Correlation of abnormal $Q$ waves, coronary pathology, and ventricular contractility. American Heart fournal, 90, 451-457.

Helfant, R., Pine, R., Meister, S., Feldman, M., Trout, R., and Banka, V. (1974). Nitroglycerin to unmask reversible asynergy: correlation with post-coronary bypass ventriculography. Circulation, 50, 108-113.

Herman, M., Heinle, R., Klein, M., and Gorlin, R. (1967). Localized disorders of myocardial contraction. New England fournal of Medicine, 277, 222-232.

Hilsenrath, J., Hamby, R., Glassman, E., and Hoffman, I. (1972). Pitfalls in prediction of coronary arterial obstruction from patterns of anterior infarction on electrocardiogram and vectorcardiogram. American fournal of Cardiology, 29, 164-170.

Hilsenrath, J., Tabrah, F., Hamby, R., and Hoffman, I. (1975). Relation of left ventricular contractile patterns in coronary artery disease to the electrocardiogram and vectorcardiogram. Fournal of Electrocardiology, 8 (4), 335-342.

Jacobs, J., Feigenbaum, H., Corya, B., and Phillips, J. (1973). Detection of left ventricular asynergy by echocardiography. Circulation, 48, 263-271.

Likoff, W., Kasparian, H., Segal, B., Novack, P., and Lehman, J. (1965). Clinical correlation of coronary angiography. American fournal of Cardiology, 16, 159-164.

Martinez-Rios, M., Da Costa, B., Cecena-Seldner, F., and Gensini, G. (1970). Normal electrocardiogram in the presence of severe coronary artery disease. American Fournal of Cardiology, 25, 320-324.

Miller, R., Amsterdam, E., Bogren, H., Massumi, R., Zelis, R., and Mason, D. (1974). Electrocardiographic and cineangiographic correlations in assessment of the location, nature and extent of abnormal left ventricular segmental contraction in coronary artery disease. Circulation, 49, 447-454.

Proudfit, W., Shirey, E., and Sones, F. (1966). Selective cinecoronary arteriography: correlation with clinical findings in 1,000 patients. Circulation, 33, 901-910.

Sandler, H., and Dodge, H. (1968). The use of single plane angiocardiograms for the calculation of left ventricular volume in man. American Heart fournal, 75, 325-334.

Simonson, E. (1961). Differentiation Between Normal and Abnormal in Electrocardiography. C. V. Mosby, St. Louis.

Teichholz, L. E., Cohen, M., Sonnenblick, E., and Gorlin, R. (1973). Detection of abnormalities of left ventricular wall motion by B scan ultrasonography. Circulation, 47 and 48, Suppl. IV, IV-127.

Welch, C., Proudfit, W., Sones, F., Shirey, E. K., Sheldon, W. C., and Razari, M., 1970). Cine-coronary arteriography in young men. Circulation, 42, 647. 
Weissler, A., Lewis, R., and Leighton, R. (1972). The systolic time intervals as a measure of left ventricular performance in man. In Progress in Cardiology, Vol. I, p. 155. Ed. by $P$. Yu and J. Goodwin. Lea and Febiger, Philadelphia.

Williams, R., Cohn, P., Vokonas, P., Young, E., Herman, M., and Gorlin, R. (1973). Electrocardiographic, arteriographic and ventriculographic correlations in transmural myocardial infarction. American fournal of Cardiology, 31, 595-599.

Requests for reprints to Dr. Mark H. Swartz, The Mount Sinai Hospital, Division of Cardiology, 100th Street at Fifth Avenue, New York, New York 10029, USA.

\section{International Society of Cardiology}

The Council on Epidemiology and Prevention of the International Society of Cardiology announces its 10th Ten Day International Teaching Seminar on Cardiovascular Epidemiology and Prevention, to be held in Ghana, 21 August to 2 September, 1977. Approximately 30 Fellows can be accepted. Final selection will be made by the Council's Seminar Committee. Nominees should be at the postdoctoral level, with some residency training or its equivalent, and be interested in cardiovascular epidemiology. Except in unusual circumstances, preference will be given to younger candidates, with little or no formal training in epidemiology. Limited funds may be available to give partial assistance with travel costs for accepted Fellows.
Room and board are provided, without cost, to Fellows. Fluency in English is essential.

Three documents are required for application and should be sent at time of application: A letter of nomination submitted by chief of department or institution, a personal letter of application from the nominee, and the applicant's curriculum vitae. These should be received before the deadline for application, 1 May, 1977.

They should be sent to: Jeremiah Stamler, M.D., Chairman, Council on Epidemiology and Prevention, ISC, Northwestern University Medical School, Ward Building-Room 9-105

303 East Chicago Avenue,

Chicago, Illinois 60611, U.S.A. 